\title{
Manila Declaration on the Availability and use of Health Research Information in and for Low-and Middle-Income Countries in the Asia Pacific Region
}

We, the participants in the Joint Meeting of the Asia Pacific Association of Medical Journal Editors (APAME), the Index Medicus of the South East Asia Region (IMSEAR), and the Western Pacific Region Index Medicus (WPRIM) held in Manila from 24 to 26 August 2015, in conjunction with the COHRED Global Forum on Research and Innovation for Health held in Manila from 24-27 August 2015, drawing on the PreForum Discussions on HIFA from 20 July to 24 August 2015 "Meeting the information needs of researchers and users of health research in low- and middle-income countries" available at http://www.hifa2015.org/meetingthe-information-needs-of-researchers-and-users-of-health-research-2/ and the BMJ Blogs 20 July 2015 "How can we improve the availability and use of health research in developing countries?" available at http://blogs. bmj.com/bmj/2015/07/20/how-can-we-improve-the-availability-anduse-of-health-research-in-developing-countries/:

\section{CONSIDERING}

That the WHO Constitution "enshrines the highest attainable standard of health as a fundamental right of every human being;" and that "The right to health includes access to timely, acceptable, and affordable healthcare of appropriate quality in tandem with "the underlying determinants of health," including "access to health-related education and information;"

That increasing the availability of quality health research information is fundamental to the successful attainment of global health and progressive realization of the right to health; and that all healthcare stakeholders (individuals, researchers, providers, professionals, leaders and policymakers) need seamless access to peer-reviewed research and information that are relevant to their respective contexts, and presented in a language they can understand;

That despite a growing momentum towards free and open access to research literature, and important initiatives, such as HINARI Access to Research In Health Programme and IRIS Institutional Repository for Information Sharing, that have helped to improve the availability of research in low- and middle-income countries, there continue to be many challenges, limitations and exclusions that prevent health research information from becoming freely and openly available to those who need it;

That the Global Health Library (GHL), Index Medicus of the South East Asia Region (IMSEAR), Western Pacific Region Index Medicus (WPRIM), and Asia Pacific Association of Medical Journal Editors (APAME) are important collaborative initiatives that can promote and uphold the availability and use of health research information especially in and for low- and middle-income countries in the Asia Pacific Region;

\section{CONFIRM}

Our commitment to champion and advocate for the increased availability, accessibility and visibility of health research information from and to low- and middle-income developing countries through our Journals, our respective National Associations of Medical Editors, and APAME

Our commitment to make research information freely and openly available in the right language to producers and users of health research in low- and middle-income countries through IMSEAR, WPRIM, the Asia Pacific Medical Journal Articles Central Archives (APAMED Central) and other platforms;

Our commitment to improve availability, accessibility and interoperability of the different formats of health information suitable to different users in their respective contexts including through both conventional and alternative channels of research dissemination such as new and social media, mobile and disruptive technologies, blogging and microblogging tools and communities, and communities of practice; 


\section{CALL ON}

Member States of and governments in the South East Asia and Western Pacific Regions, in collaboration with stakeholders from the non-government and private sectors to formulate and implement policies and certification schemes such as the COHRED Fairness Index ${ }^{\mathrm{TM}}(\mathrm{CFI})$ that promote free and open availability of health research information for both its producers and users, especially in low- and middle-income countries;

Stakeholders from the public and private sectors, national and international organizations, universities and academic societies, and discussion groups such as Healthcare Information for All (HIFA2015) to support IMSEAR, WPRIM, the GHL, APAMED Central, and develop Integrated Scholarly Information Systems and similar initiatives, in order to ensure the free, open and global accessibility of health research done in the South East Asia and Western Pacific Regions;

The Eastern Mediterranean Association of Medical Editors (EMAME), the Forum for African Medical Editors (FAME), the European Association of Science Editors (EASE), the World Association of Medical Editors (WAME), the International Committee of Medical Journal Editors (ICMJE), the Committee on Publication Ethics (COPE) and other editors' and publishers' associations to support APAME in implementing various activities, guidelines and practices that would improve the quality, availability and accessibility of scientific writing and publications in the Asia Pacific Region and the world;

Bibliographic, Citation and Full-Text Databases such as PubMed, Global Health Database (CAB Direct), the Directory of Open Access Journals (DOAJ), EMBASE, SciELO Citation Index, Scopus, and the Web of Science to review their policies and processes for indexing Journals from low- and middle-income countries, as well as making health research information freely and openly available to users in these countries who cannot afford to pay for it;

\section{COMMIT}

Ourselves and our Journals to publishing innovative and solutionfocused research in all healthcare and related fields such as health promotion, public health, medicine, nursing, dentistry, pharmacy, other health professions, health services and health systems, particularly health research applicable to low- and middle-income countries;

Ourselves and our publishers to disseminating scientific, healthcare and medical knowledge fairly and impartially by developing and using Bibliographic Indices, Citation Databases, Full-Text Databases and Open Data Systems including, but not limited to, such Regional Indexes of the Global Health Library as IMSEAR, WPRIM and APAMED Central;

Our organization, APAME, to building collaborative networks, convening meaningful conferences, and organizing participative events to educate and empower editors, peer reviewers, authors, librarians and publishers to achieve real impact, and not just impact factor, as we advance free and open access to health information and publication that improves global health-related quality of life.

\section{August 2015, Manila Copyright $\odot$ APAME. www.wpro.who.int/apame apame@wpro.who.int}

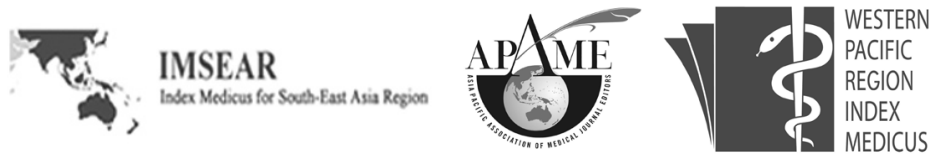

This declaration was launched at the 2015 Convention of the Asia Pacific Association of Medical Journal Editors (APAME) held in Manila from 24 to 26 August 2015. It is concurrently published by Journals linked to APAME and listed in the Index Medicus of the South East Asia Region (IMSEAR) and the Western Pacific Region Index Medicus (WPRIM). 